\title{
FEMALE URINARY RETENTION: OBSERVATIONS FROM A RETROSPECTIVE CASE NOTE REVIEW
}

Aman Khela'; Ayooluwa Olateju²; Thiruendran Gunendran ${ }^{3}$; Richard J, Montague ${ }^{3}$

${ }^{1}$ Department of Urology, Birmingham City Hospital, Dudley Road, Birmingham, UK.

${ }^{2}$ Department of Obstetrics and Gynaecology, St Mary's Hospital, Manchester, UK.

${ }^{3}$ Department of Urology, Wythenshawe Hospital, Manchester, UK.

Corresponding Author: aman.khela@nhs.net

Submitted: December 23, 2019. Accepted: January 25, 2020. Published: May 8, 2019.

\begin{abstract}
Background and Objective

There are no current guidelines to manage female retention patients. We aimed to see if a standardized approach could be used to manage these patients.
\end{abstract}

\section{Methods}

Between October 2014 and September 2016, all female patients with urinary retention admitted under a urology consultant were reviewed.

\section{Results}

A total of 46 females had a single episode of urinary retention whilst 19 females had recurrent episodes. The commonest cause for a single episode of retention was attributed to anesthesia (general/spinal) ( $\mathrm{n}=9$ ), constipation ( $\mathrm{n}=9)$ and medication use $(\mathrm{n}=4)$. Most of these women $(95 \%)$ voided on the first attempt following catheter removal. In the absence of any neurological symptoms, pelvic ultrasound was the only investigation that revealed any underlying pathology in female retention patients. A pelvic mass was identified in $3(4.5 \%)$ patients.

\section{Conclusion}

Females with an isolated episode of retention, with an obvious precipitating cause identified during full history and examination, could proceed directly to a nurse-led trial of catheter removal without the need for any further urology review. Others should undergo a pelvic ultrasound and review by a urologist. In our opinion, females with recurrent unexplained episodes of urinary retention should be referred for a trial of sacral neuromodulation if considered appropriate.

Female urinary retention is a relatively uncommon with an incidence of 3 per 100,000 and female to male ratio of $1: 13 .{ }^{1}$ Retention has been defined as the difficulty to self-void, leading to an inability to achieve complete bladder emptying. Retention in females is less common than in males due to anatomical differences of the urological tract, making bladder outflow obstruction less likely. For some females, retention can be chronic and an incidental finding while in others it can be acute, leading to a painful distended abdomen. The causes of female retention are diverse and poorly understood. There is no standardized approach to investigating and managing females who present with urinary retention. Several papers have 
attempted to classify the causes of female retention, but no consensus on classification and management has been reached. ${ }^{2-4}$

Our primary aim is to try and identify common causes of female urinary retention within our institution and to standardize our practice. The primary outcome is to establish a pathway to manage these patients and to reach a consensus on what investigations are useful and necessary for these patients.

\section{METHODS}

We identified female patients who presented between October 2014 and September 2016 with urinary retention. We only included patients with a urology consultant assigned to their care. Accident and Emergency (A\&E) records, inpatient notes, clinic letters and test results from the first presentation until discharge, or the end of data collection (31/12/2017), were reviewed. A\&E and inpatient notes were examined for presenting complaints, examination findings, urinalysis results, initial working diagnosis, and post catheterization residuals. Notes and letters were analyzed to understand the patient journey, the rationale behind the requested tests and to determine outcomes after a Trial With Out Catheter (TWOC). Test results, including scans and urine microbiology, were reviewed for contributing pathology.

We defined acute retention as abdominal pain and distension that was relieved by catheterization irrespective of the volume of urine drained. We defined chronic retention as a painless post-void residual of over $300 \mathrm{~mL}$. Idiopathic retainers were defined as females with recurrent unprecipitated episodes of retention and normal investigations.

\section{RESULTS}

Our coding department classified 132 episodes as female urinary retention. Of the 132 cases, 28 (21\%) cases were excluded due to being wrongly coded and pertained to females attending for intravesical instillations or catheter changes. A further $17(12 \%)$ cases were excluded (Figure 1). Three patients were already known to have chronic retention while 5 patients had incidental large residuals on catheterization for fluid balance monitoring. The other $9(6 \%)$ excluded females were oliguric with small residuals upon

FIG. 1 Demonstrating the breakdown of all 132 records.

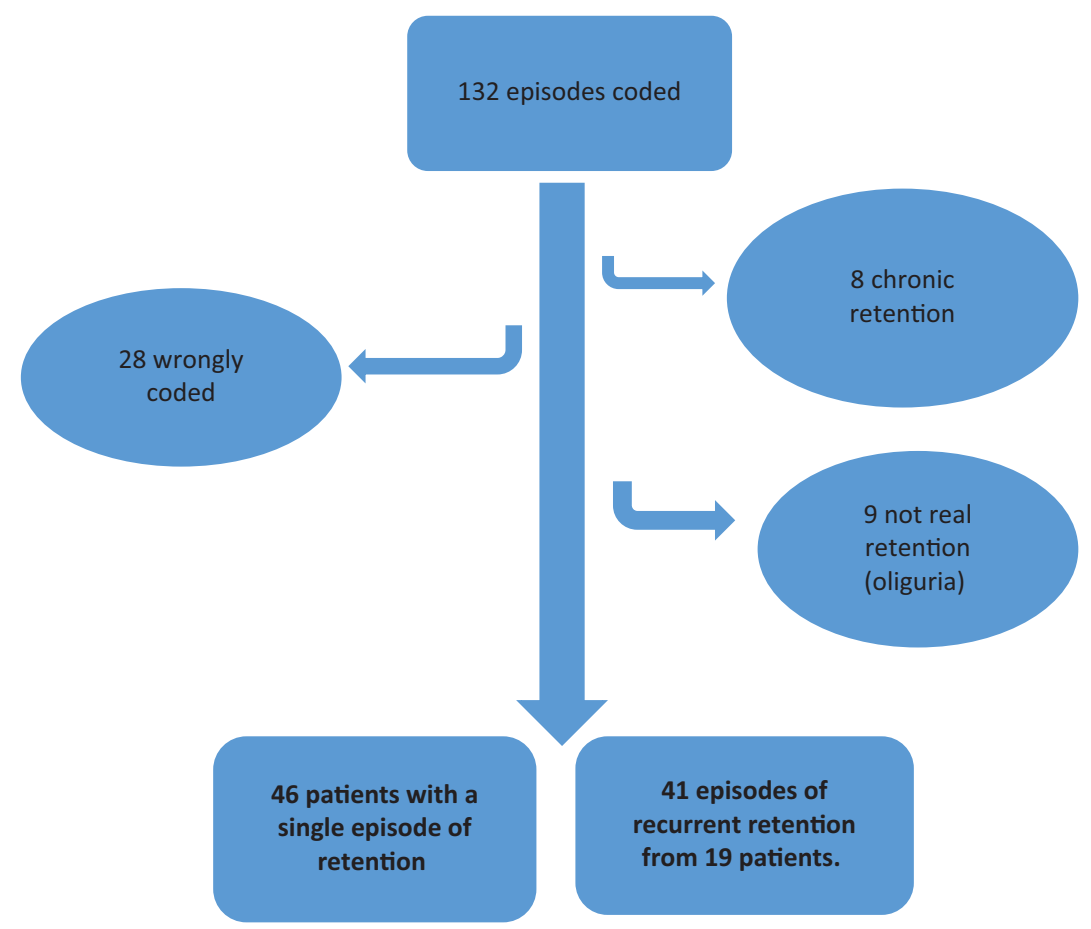

J Endolum Endourol Vol 3(1):e5-e15; May 8, 2020.

This article is distributed under the terms of the Creative Commons Attribution-Non Commercial 4.0 International License. (c) Khela, et al. 
TABLE 1 Demographics of Patients in the Study

\begin{tabular}{|l|l|l|}
\hline & \multicolumn{1}{|c|}{ Single Episode of Retention } & Recurrent Episodes of Retention \\
\hline $\begin{array}{l}\text { Number of patients } \\
\text { (65 patients) }\end{array}$ & 46 patients & 19 patients \\
\hline $\begin{array}{l}\text { Retention episodes } \\
(87 \text { episodes })\end{array}$ & Accounting for 46 single episodes & Accounting for 41 episodes \\
\hline Age range in years & $17-92$ (mean 53 years) & $18-83$ (mean 38 years) \\
\hline
\end{tabular}

catheterization. These 45 cases were excluded from the analysis.

After review of the A\&E records, there were 65 patients identified in total with female urinary retention. Of these patients, 46 females (71\%) presented with a first and single episode of retention. The remaining 41 episodes were as a result of 19 female patients presenting with more than one episode of retention (recurrent retention) between October 2014 and September 2016. The demographics of our patient population is outlined in Table 1 .

\section{Single Episode of Retention: Causes}

We reviewed the A\&E case notes of patients presenting with retention. In the majority of cases, the episode of retention was attributed to a urinary tract infection $(22 \%, n=10)$, constipation $(20 \%, n=9)$ or recent anesthesia $(17 \%, n=8)$. Subsequent investigations by urology, however, did not always agree with the initial diagnosis and the discrepancies are outlined in Table 2. We also found that examination findings were documented poorly with only $19(23 \%)$ of the 65 females in the study having a neurological examination performed at presentation.

We found several potential contributory factors for female retention, the commonest being constipation (9 patients) or recent anesthesia (9 patients). Of the 9 females with post-operative retention, 3 had recently undergone urogynaecological surgery whilst the other 6 had either a general surgical or orthopedic procedure. Although a urinary tract infection UTI was cited as the contributory factor in 10 cases, often there were no cultures sent. 3 patients presented after starting an anti-cholinergic and 1 patient was unable to void following intravesical botox. Several other contributory factors are outlined in Table 2. Although these triggers are often difficult to prove with certainty, we found that after correcting and eliminating these factors the patients were able to void successfully.

\section{Single episode of Retention: Investigations}

Of the 46 females with a single episode of urinary retention, 19 (41\%) had no imaging or invasive investigations. The other 27 (59\%) had a combination of ultrasound (USS) and / or magnetic resonance imaging (MRI). We found no standardized approach to the body areas imaged. The scans requested were diverse as highlighted by Table 3 . The use of cystoscopy as part of the diagnostic investigations was also variable with $14(30 \%)$ patients having either a flexible or rigid cystoscopy while 2 had both. Only 2 patients were referred for urodynamics (UDS) and it is unclear on what basis this decision was made. Both of these patients had an underactive bladder.

There was little consistency or relationship between presumed etiology of retention, examination findings and the mode of imaging requested. Only 3 patients (6\%) had a positive finding on USS imaging of a pelvic mass. 2 females had large fibroids and 1 had a large ovarian cyst. Women with a history of recurrent UTIs were more likely to undergo a USS.

An MRI of the spine was performed in 10 females while 1 patient also had a concomitant MRI head. Only one patient was known to have multiple sclerosis, none of the other females had neurological symptoms although only 6 had a documented neurological exam.

\section{Single Episode of Retention: Outcomes}

Out of the 46 patients who presented following their first episode of retention, $32(70 \%)$ voided 
TABLE 2 Summary of Reasons Cited as Causing Retention and How the Diagnosis Changed Following Reassessment and Investigation By Urology

\begin{tabular}{|c|c|c|c|}
\hline $\begin{array}{l}\text { Initial Working } \\
\text { Diagnosis }\end{array}$ & $\begin{array}{l}\text { Number } \\
\text { of } \\
\text { Patients }\end{array}$ & $\begin{array}{c}\text { Number (\%) of Patients with } \\
\text { Same Diagnosis } \\
\text { After Investigations }\end{array}$ & $\begin{array}{c}\text { Number of Patients with an } \\
\text { Alternative Diagnosis } \\
\text { After Investigations }\end{array}$ \\
\hline UTI & $10(22 \%)$ & $3(30 \%)$ & $\begin{array}{l}\text { Chronic retention }-3(30 \%) \\
\text { Triggered by chemotherapy }-1 \\
(10 \%) \\
\text { Idiopathic }-1(10 \%) \text { Progression of } \\
\text { MS - } 1(10 \%) \text { Post-surgery - } \\
1(10 \%)\end{array}$ \\
\hline Constipation & $9(20 \%)$ & $7(78 \%)$ & Chronic retention - 2 (22\%) Post \\
\hline $\begin{array}{l}\text { anesthesia } \\
\text { (post-operative) }\end{array}$ & $8(17 \%)$ & $8(100 \%)$ & - \\
\hline Medication induced & $4(9 \%)$ & $\begin{array}{l}3 \text { anti-cholinergic use }(75 \%) \\
1 \text { post botox }(25 \%)\end{array}$ & - \\
\hline Idiopathic & $4(9 \%)$ & $1(25 \%)$ & $\begin{array}{l}\text { Chronic retention }-2(50 \%) \\
\text { Constipation - } 1(25 \%)\end{array}$ \\
\hline $\begin{array}{l}\text { Post-partum (perineal } \\
\text { injury) }\end{array}$ & $3(7 \%)$ & $3(100 \%)$ & - \\
\hline Neurological & $2(4 \%)$ & $1(50 \%)$ & Chronic retention - 1 (50\%) \\
\hline Opioid induced & $1(2 \%)$ & 0 & Constipation - $1(100 \%)$ \\
\hline Pregnancy related & $1(2 \%)$ & $1(100 \%)$ & - \\
\hline Alcohol induced & $1(2 \%)$ & 0 & $\begin{array}{l}\text { Pelvic mass - } 1(100 \%) \\
\text { (uterine fibroid) }\end{array}$ \\
\hline Pelvic mass & $1(2 \%)$ & $1(100)$ & - \\
\hline Prolapse & $1(2 \%)$ & 0 & $\begin{array}{l}\text { Pelvic mass }-1(100 \%) \\
\text { (ovarian cyst) }\end{array}$ \\
\hline
\end{tabular}

successfully after catheter removal although 6 were required to intermittently perform ISC. Three females had a pelvic mass that required treatment before they could resume spontaneous voiding while the other 3 patients eventually managed to discontinue selfcatheterization after a few weeks. The other $14(30 \%)$ failed to void and required long term catheters or still perform ISC. One patient had a diagnosis of Fowlers syndrome following previous sphincter EMG and was re-established on ISC after catheter removal. She was awaiting a trial of sacral neuromodulation elsewhere. Table 4 shows the breakdown of outcomes based on working diagnosis.

Of the 22 females who were thought to have a contributory trigger factor such as constipation, medication use, recent anesthesia, or urogynaecological surgery 21 
TABLE 3 Variability in Imaging Requested for Females in Retention

\begin{tabular}{|l|c||l|c|}
\hline \multicolumn{1}{|c|}{ USS Imaging } & Number & \multicolumn{1}{|c|}{ MRI Imaging } & Number \\
\hline None & $22(47 \%)$ & None & $36(78 \%)$ \\
\hline USS renal tract (RT) & 9 & MRI whole spine & 4 \\
\hline USS Abdomen / Pelvis & 5 & MRI thoraco-lumbar spine & 1 \\
\hline USS RT / Abdomen / Pelvis & 5 & MRI lumbar spine & 3 \\
\hline USS RT / Abdomen & 2 & MRI pelvis & 2 \\
\hline USS RT / Pelvis & 3 & MRI head & 1 \\
\hline
\end{tabular}

$M R I=$ magnetic resonance imaging; $R T=$ renal tract USS = ultrasound.

TABLE 4 Demographics and Outcomes of Females Presenting with a Single Episode of Retention

\begin{tabular}{|c|c|c|c|c|}
\hline $\begin{array}{l}\text { Urology } \\
\text { Diagnosis }\end{array}$ & Number & $\begin{array}{l}\text { Average Age } \\
\text { (years) }\end{array}$ & Range & Outcome \\
\hline UTI & 3 & 46 & $30-86$ & 2 Voiding / 1 LTC \\
\hline Constipation & 9 & 60 & $30-79$ & 9 Voiding \\
\hline Post-surgery & 9 & 55 & $18-87$ & 8 Voiding / 1 ISC (TVTO) \\
\hline $\begin{array}{l}\text { Anticholinergic / Botox } \\
\text { induced }\end{array}$ & 4 & 66 & $18-91$ & 4 Voiding \\
\hline $\begin{array}{l}\text { No cause found / } \\
\text { Idiopathic }\end{array}$ & 2 & 59 & $35-83$ & 2 Voiding, 1 required short term ISC \\
\hline Post-partum & 3 & 33 & $31-34$ & 3 Voiding, 2 required short term ISC \\
\hline $\begin{array}{l}\text { Neurological } \\
\text { (progression of MS) }\end{array}$ & 2 & 40 & $17-64$ & 1 LTC, 1 ongoing ISC \\
\hline Fowlers & 1 & 22 & 22 & Referred back to original trust/urologist \\
\hline Pregnancy & 1 & 34 & 34 & $\begin{array}{l}\text { Voiding post pregnancy (LTC during, unable to } \\
\text { ISC) }\end{array}$ \\
\hline Pelvic mass & 3 & 55 & $44-70$ & $\begin{array}{l}\text { Short-term ISC / LTC. All } 3 \text { spontaneously } \\
\text { voiding post treatment of mass }\end{array}$ \\
\hline Chronic retention & 8 & 68 & $20-92$ & ISC 3, 5 LTC \\
\hline Post chemotherapy & 1 & 47 & 47 & $\begin{array}{l}\text { CISC post chemotherapy, Voiding normally } \\
\text { in-between }\end{array}$ \\
\hline
\end{tabular}

(95\%) voided successfully following catheter removal. There was one patient who had a recent insertion of a TVT-O who remained in retention and was referred back to their urogynaecologist.

\section{Recurrent Episodes of Retention: Causes and Management}

Nineteen females presented with recurrent episodes of urinary retention. These contributed to 41

J Endolum Endourol Vol 3(1):e5-e15; May 8, 2020. 
TABLE 5 Causes of Recurrent Retention and the Ongoing Management of These Females

\begin{tabular}{|l|c|c|l|}
\hline \multicolumn{1}{|c|}{ Diagnosis } & Number of Patients & Average Age (range) & \multicolumn{1}{c|}{ Ongoing Management } \\
\hline Idiopathic & $10(55 \%)$ & $38(18-86)$ & $\begin{array}{l}1 \text { SPC } \\
9 \text { taught CISC }\end{array}$ \\
\hline Constipation & $2(10 \%)$ & $35(27-43)$ & Discharged able to CISC \\
\hline $\begin{array}{l}\text { Drug-induced } \\
\text { (psychotropic) }\end{array}$ & $2(10 \%)$ & $25(23-27)$ & Discharged able to CISC \\
\hline Neurological & $2(10 \%)$ & $40(37-43)$ & Discharged able to CISC \\
\hline UTI & $1(5 \%)$ & 30 & Discharged able to CISC \\
\hline Pregnancy & $1(5 \%)$ & 24 & Discharged able to CISC \\
\hline Post-Surgery & $1(5 \%)$ & 83 & Discharged able to CISC \\
\hline
\end{tabular}

$D N A=$ did not attend; ISC = intermittent self catheterization; LTC = long term catheter; SPC = suprapubic catheter.

coded retention episodes in our series. Many of these patients did not have any apparent contributory factors and none were unable to spontaneously void as illustrated in Table 5. A few women in the idiopathic retention group struggled with ISC and presented to A\&E several times due to difficulty self-catheterizing. These patients were also more likely to have chronic abdominal and pelvic pain according to their records.

\section{RECURRENT EPISODES OF RETENTION: INVESTIGATION}

We found that females with recurrent episodes of retention were more likely to undergo repeated scans and multiple investigations. All 19 patients underwent some form of imaging over the course of the 41 episodes of retention. In 9 patients, an MRI scan of the spine and an ultrasound (abdomen, renal tract or pelvis) was performed during the same admission episode. The other patients had either an ultrasound scan $(84 \%, n=16)$ or MRI scan $(68 \%, n=13)$ during one of their retention episodes. There was once again a huge variety in the area scanned. Flexible cystoscopy was performed in $9(47 \%)$ females while 3 patients went on to have a rigid cystoscopy and urethral dilatation. In the idiopathic group, 3 of the 10 patients underwent video urodynamics. It is unclear why these 3 patients were referred for urodynamics studies while the other 7 were not.

\section{DISCUSSION}

Urinary retention in women is uncommon and the etiology can be multifactorial. The International Urogynecological Association (IUGA)/International Continence Society defines urinary retention as the complaint of the inability to pass urine despite the persistent effort. Agreement as to what constitutes a clinically significant post-void residual has not been defined and current definitions do not include an objective volume. Retention can be acute or chronic and it may be symptomatic or asymptomatic.

As female urinary retention is rare, there is a large variability in the management of these patients with a lack of consensus regarding their investigations. There appears to be a wide range of tests that these women are subjected to. We hope that our large series of cases will provide a basis for future recommendations and help provide some direction for investigations in such patients.

\section{Single Retention Episode: Precipitating Factors}

Unlike men where bladder outlet obstruction is common, female urinary retention is more likely to have a precipitating contributory factor. These trigger factors are often transient and a well-directed initial history can help in trying to identify this. From our observations, we found that a significant proportion of women who present with their first episode of 
retention have a contributory cause for their retention. Many of these causes are transient and easily corrected. Constipation, the use of certain medication and anesthesia appear to be common triggers for female urinary retention and the findings in our series are similar to other studies. ${ }^{6-8}$

We found that post-operative female urinary retention was common following urogynaecological or general surgical procedures and to a lesser extent post-orthopedic surgery. However, the number of cases in our series was too low to draw any meaningful conclusion about the specific type of surgical procedure itself that increased this risk. In a review article, Baldini et al reported an increased risk of retention post anorectal surgery and after hernia repair while retention post gynecological surgery had conflicting results. Previous pelvic surgery also increased this risk, probably due to direct damage to the nerves innervating the lower urinary tract. ${ }^{7}$ General anesthesia itself can be a contributing factor as the analgesic drugs can disrupt the neural pathways involved in micturition. Once the effects of anesthesia or surgery have worn off, the chances of successful voiding following catheter removal are high. Studies have shown that many of these women will have no long-term adverse effect. ${ }^{9-11 .}$

Post-partum retention is commonly defined as the inability to spontaneously void after 6 hours of childbirth. Retention after childbirth is well documented and may often not be recognized until much later. ${ }^{9,10}$ Following vaginal delivery, this risk has been shown to increase with prolonged duration of the second stage of labour, birth weight $>4 \mathrm{~kg}$, presence of episiotomy and perineal laceration. ${ }^{12}$ Third stage duration, time from birth to the first void, and number of peri-partum micturitions have also been found to be potential risk factors for post-partum urinary retention. ${ }^{12}$ In our series, all the three women who developed postpartum urinary retention sustained a perineal injury and resumed spontaneous voiding within a few weeks.

\section{Single Retention Episode: Investigations}

Aside from a thorough initial history, clinical examination is equally important especially about determining an underlying cause for the retention episode. An abdominal, vaginal and rectal examination can help pick up potential causes such as a pelvic mass, pelvic organ prolapse, urethral abnormality or constipation. A neurological examination should also be performed in all females presented with retention.

Previously published papers suggest that a detailed history and examination is often all that is required to establish the cause of retention. ${ }^{4,13,14}$ Some authors have advocated the use of an ultrasound scan and either a flexible ${ }^{4,13}$ or a rigid cystoscopy ${ }^{14}$ in the further investigation of these females. In our series, ultrasound imaging only revealed pathology in 3 of the 65 females while none of the cystoscopies revealed any cause for the retention. Of the 3 patients where an abnormality was found on ultrasound, it was related to a pelvic mass (incidental in 2 patients, suspected in 1 patient). Hence, we recommend that an ultrasound scan of the pelvis is reserved for patients with no history of any contributory triggers for the retention episode or when there is clinical suspicion of a pelvic mass. Ultrasound scans of the renal tract were normal in all patients. We feel that routine USS imaging in the presence of normal examination and renal function is unnecessary and unlikely to yield new information as previously reported in some other studies ${ }^{4}$. The caveat to this would be unless the history would suggest a USS to be useful, such as in the context of recurrent UTIs.

We found that the use of MRI scans to be very variable. The area scanned differed enormously as previously outlined in Table 3. In our series some women had an MRI performed on the presentation while others at a later stage. An MRI scan of the spine was performed urgently in 1 patient with suspected cauda equina. In the other 7 patients who underwent an MRI scan of their spine, no neurology was documented. None of the 8 scans identified any focal abnormality to explain the retention episode. Our findings suggest that in the absence of any neurological signs or symptoms, an MRI scan of the spine is not required.

Ahmad et al found urethral stenosis to be the cause of retention for many of their female patients. ${ }^{14}$ This diagnosis was only made after cystoscopy. Urethral stenosis is more common in post-menopausal women secondary to urogenital atrophy caused by hormonal insufficiency. Urethral stenosis can also be caused by postoperative scarring or urethral/urogenital cancers. In our series, of the 25 females that underwent a

J Endolum Endourol Vol 3(1):e5-e15; May 8, 2020.

This article is distributed under the terms of the Creative Commons Attribution-Non Commercial 4.0 International License. (c) Khela, et al. 
cystoscopy, no abnormality was identified. Moreover, none were able to void spontaneously after this despite some patients undergoing a urethral dilation. From our review of literature, there is insufficient evidence to support a routine cystoscopy in all female retention patients. We would advocate this if catheterization was difficult or if there were clinical features to justify this (e.g., hematuria, recurrent UTIs or urethral abnormality). It should also be considered in women with previous antiincontinence surgery. If there is a history of surgery for stress incontinence, timely intervention is crucial as delaying intervention beyond one month may result in a permanent impairment as a consequence of urethral fibrosis. ${ }^{3}$ Also, it would be reasonable to perform a cystoscopy if there was a prodromal history of voiding symptoms such as hesitancy, straining, a poor urinary stream and sensation of incomplete bladder emptying. In our series, 2 patients were referred for video urodynamic studies following their first episode of retention. Both these women were self-catheterizing and did not exhibit any symptoms suggestive of obstruction. There was no change in their management following urodynamics either although several studies have talked about its use in diagnosing female bladder outlet obstruction. ${ }^{15,16}$ It is however important to point out that there are no standardized or widely accepted criteria for diagnosing bladder outlet obstruction in women.

From our series, we could not identify a standardized approach to investigate women who present with urinary retention. The history, examination, and investigations varied widely with no rationale behind some of these tests.

FIG. 2 Proposed algorithm for the management of females presenting in retention for the first time.

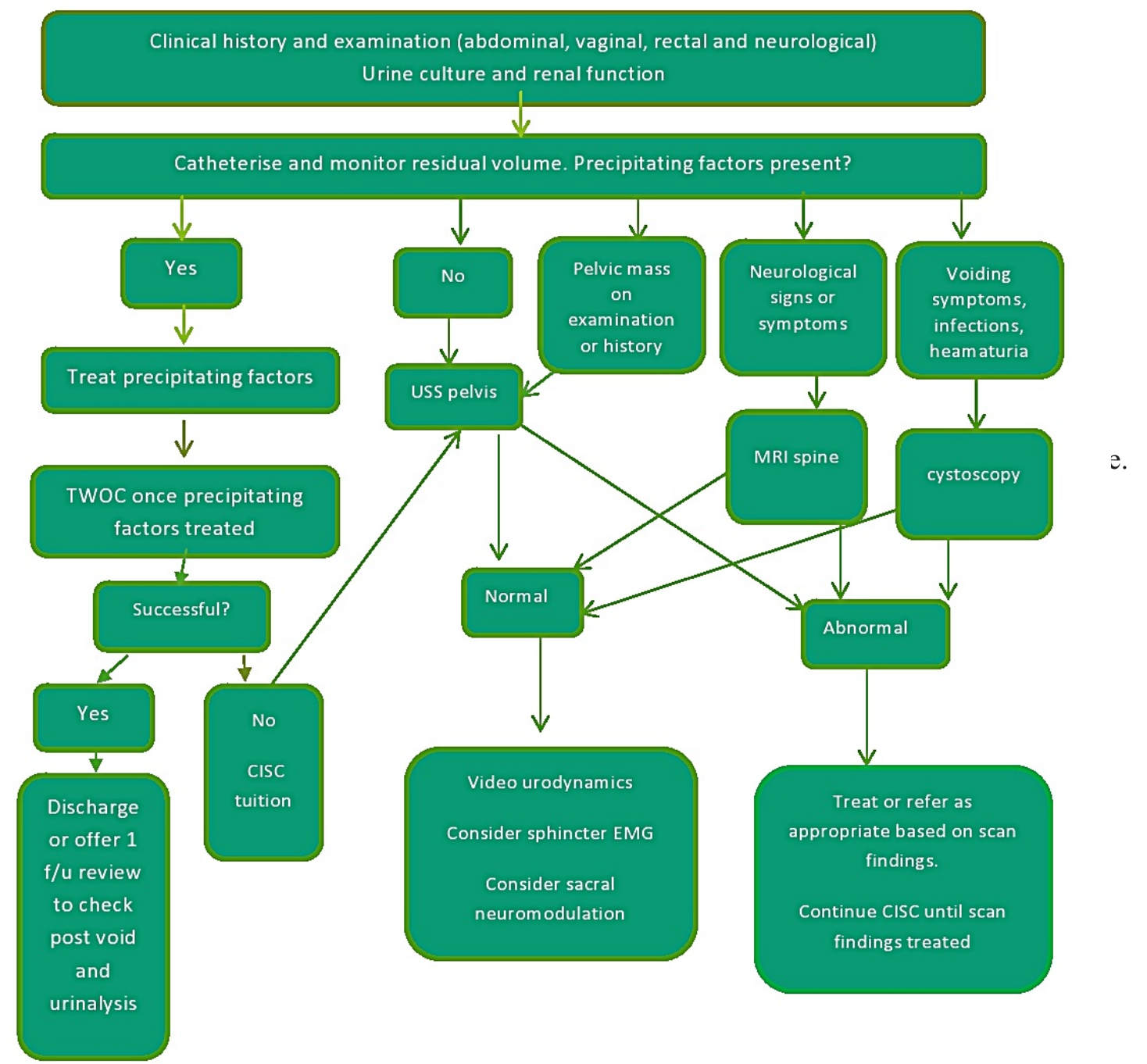


There was little consistency between the presumed etiology of retention and the imaging requested. The inter-clinician variability is almost certainly a reflection of the heterogeneous etiology underlying the condition and the lack of standardization in managing these patients. Based on the findings from our case series and the literature we would like to propose the following algorithm (Figure 2), in the management of females presenting with a single episode of retention.

Many hospitals already have nurse-led TWOC clinics available and it would be worthwhile utilizing this service in the management of females with acute retention. Due to the heterogeneity of underlying causes, it would be prudent to ensure that females were only booked in for nurse-led TWOCS provided they have been properly and thoroughly assessed beforehand and a reversible cause for their retention found. As Figure 2 shows if this subset of women passes their TWOC they can be discharged from the services. Any subsequent presentations would require review in a urology clinic. The other group of women requiring a clinic review would be those who were inadequately assessed and examined before being catheterized or those where a cause for the retention has not been identified. These females should be diverted back into a urology clinic for their history to be reviewed and the appropriate examinations and follow up investigations performed either before or after a TWOC

\section{Recurrent Retention Episode}

Patients with recurrent retention episodes may be more likely to suffer from bladder dysfunction. Some women present with recurrent intermittent episodes of urinary retention with intervening periods of normal voiding. It is often difficult to manage these women and in the absence of any overt pathology or trigger, the retention may be incorrectly attributed to a psychogenic cause. ${ }^{17}$ This is commonly described as the inability to pass urine voluntarily, without any discomfort or urge to pass urine. In our series, patients with the previous retention were less likely to have a trigger factor. In 10 of the 19 patients with recurrent retention, no contributory factor was identified compared to only 4 out of the 46 in the first retention episode group. Many classifications have been postulated suggest that early referral could avoid disengagement with the health service through frustration. ${ }^{20-23}$ Patients who manifest the typical characteristics of Fowler's syndrome on sphincter EMG would be candidates for sacral neuromodulation which may be able to restore voiding in a significant proportion of women affected. However, this may not always be appropriate, suitable or acceptable to the patient. In patients who are unable to CISC or not suitable for sacral neuromodulation, a suprapubic catheter insertion could be contemplated. Reconstructive surgery such as a continent diversion (Mitrofanoff) or a urinary diversion remains the last resort.

Some studies have described botulinum toxin injections into the sphincter, alpha-blocker therapy and bethanechol use but there is a lack of evidence to support this and hence not recommended outside the setting of a clinical trial. Hopefully, ongoing research into this field may provide alternative effective therapies in the future. For now, based on the available literature and the findings of this case series we would like to recommend the following algorithm, Figure 3, for the management of females who present with recurrent retention. 
FIG. 3 Proposed algorithm for the management of females presenting on more than one occasion with retention.

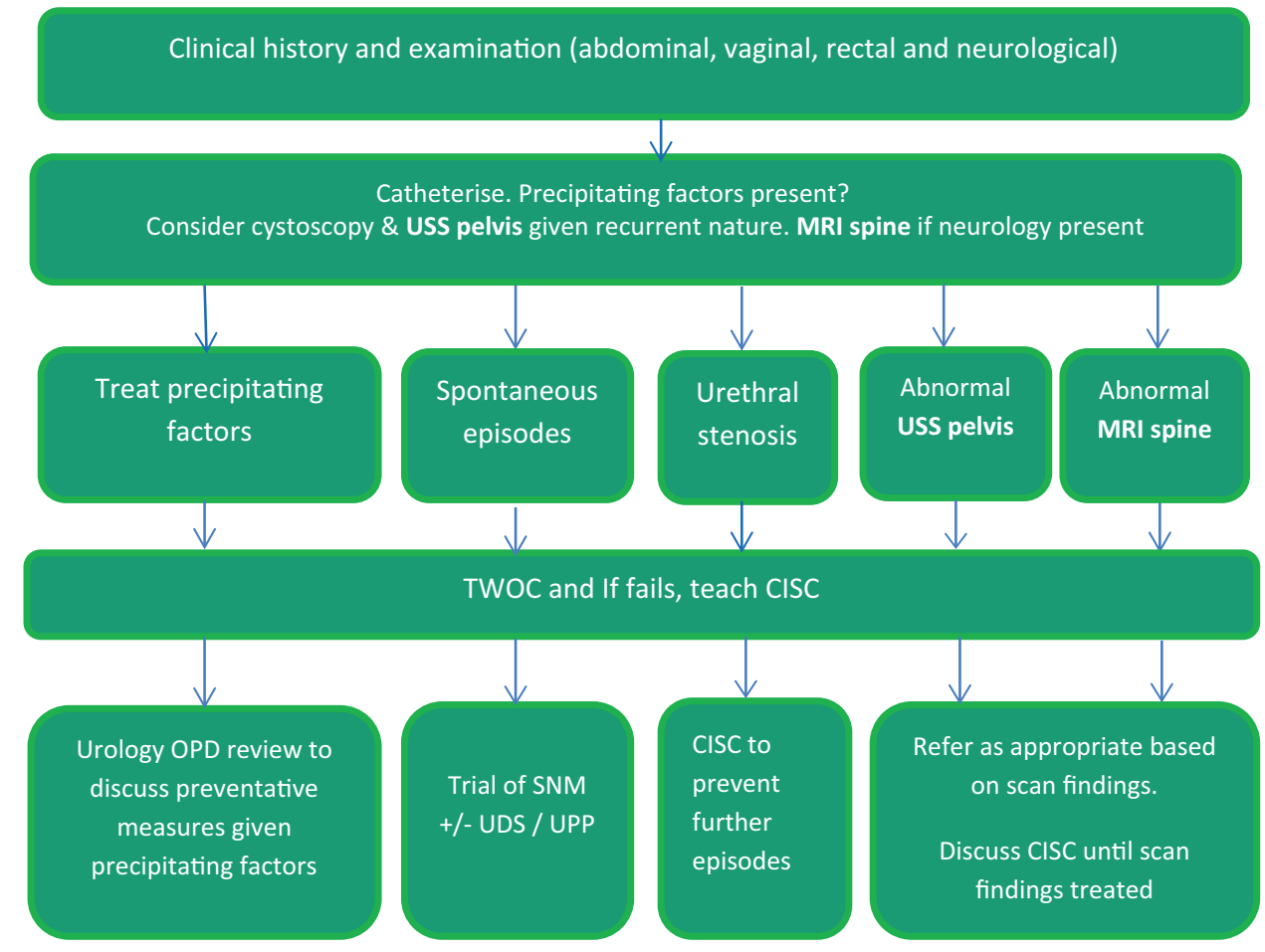

\section{CONCLUSION}

Female urinary retention is rare and poorly understood due to the heterogeneity of underlying etiologies. The investigation and management are so varied and unstandardized that it is not surprising that there is little consensus about the management of this clinical problem. Based on our series, a review of the literature and feedback from national meetings, we believe our suggested algorithms for the management of single and recurrent episodes of retention are a useful tool to help those presented with these rare but important clinical scenarios.

\section{DISCLOSURE}

No grant support was received for this article.

\section{REFERENCES}

1. Klarskov P, Andersen J, Asmussen C, Brenoe J, Jensen $\mathrm{S}$, Jensen I, et al. Acute urinary retention in women: A prospective study of 18 consecutive cases. Scand J Urol Nephrol 1987;21:29-31.

2. van der Linden EF, Venema PL. [Acute urinary retention in women]. Ned Tijdschr Geneeskd 1998 Jul;142(28):1603-6.

3. Mevcha A, Drake MJ. Etiology and management of urinary retention in women. Indian J Urol [Internet] 2010;26(2):230-5. Available from: http://www.indian jurol.com/article.asp?issn $=0970-1591$; year $=2010$; volume $=26$; issue $=2$; spage $=230$; epage $=235$; aulast $=$ mevcha 
4. Basson J, Van Der Walt C, Heyns CF. Urinary retention in women. Contin Med Educ 2012;30(5):160-2.

5. Abrams P, Cardozo L, Fall M, Griffiths D, Rosier P, Ulmsten $\mathrm{U}$, et al. The standardisation of terminology in lower urinary tract function: Report from the standardisation sub-committee of the International Continence Society. Urology 2003;61(1):37-49.

6. Lee SJ, Kim YT, Lee TY, Woo YN. Analysis of Risk Factors for Acute Urinary Retention after Non-urogenital Surgery. Korean J Urol [Internet] 2007 Dec;48(12):1277-84. Available from: http://synapse.koreamed.org/DOIx.ph $\mathrm{p}$ ?id=10.4111\%2Fkju.2007.48.12.1277

7. Baldini G, Bagry H, Aprikian A, Carli F. Postoperative urinary retention: anesthetic and perioperative considerations. Anesthesiology 2009 May;110(5):1139-57.

8. Özveren B, Keskin S. Presentation and prognosis of female acute urinary retention: Analysis of an unusual clinical condition in outpatients. Urol Ann [Internet] 2016 Jun 17;8(4):444-8. Available from: http://www .ncbi.nlm.nih.gov/pmc/articles/PMC5100150/

9. Carley ME, Carley JM, Vasdev G, Lesnick TG, Webb MJ, Ramin KD, et al. Factors that are associated with clinically overt postpartum urinary retention after vaginal delivery. Am J Obstet Gynecol 2002 Aug;187(2):430-3.

10. Geller EJ. Prevention and management of postoperative urinary retention after urogynecologic surgery. Int $\mathbf{J}$ Womens Health 2014;6(1):829-38.

11. Bouhours AC, Bigot P, Orsat M, Hoarau N, Descamps P, Fournie A, et al. [Postpartum urinary retention]. Prog Urol 2011 Jan;21(1):11-7.

12. Cavkaytar S, Kokanalı MK, Baylas A, et al. Postpartum urinary retention after vaginal delivery: Assessment of risk factors in a case-control study. J Turkish German Gynecol Assoc 2014;15(3):140-43. doi:10.5152/ jtgga.2014.13102

13. Ramsey S, Palmer M. The management of female urinary retention. Int Urol Nephrol 2006;38(3-4):533-5.

14. Ahmad I, Krishna NS, Small DR, Conn, IG. Aetiology and management of acute female urinary retention. $\mathrm{Br}$ J Med Surg Urol 2009;2:27-33
15. Nitti VW, Tu LM, Gitlin J. Diagnosing Bladder Outlet Obstruction in Women. J Urol 1999;161(5):1535-40.

16. Cormier L, Ferchaud J, Galas JM, Guillemin F, Mangin P. Diagnosis of female bladder outlet obstruction and relevance of the parameter area under the curve of detrusor pressure during voiding: preliminary results. J Urol 2002;167(5):2083-7.

17. Ryuji S, Tomoyuki U, Yusuke A, et al. Psychogenic urinary dysfunction: A uro-neurological assessment. Neurourol Urodyn [Internet] 2007 Mar 13;26(4):518-24. Available from: https://doi.org/10.1002/nau.20321

18. Fowler CJ, Kirby RS. Abnormal electromyographic activity (decelerating burst and complex repetitive discharges) in the striated muscle of the urethral sphincter in 5 women with persisting urinary retention. Br J Urol 1985 Feb;57(1):67-70.

19. Osman NI, Esperto F, Chapple CR. Detrusor underactivity and the underactive bladder: a systematic review of preclinical and clinical studies. Eur Urol 2018;74(5):633-43.

20. Cohn JA, Brown ET, Kaufman MR, Dmochowski RR, Reynolds WS. Underactive bladder in women: is there any evidence? Curr Opin Urol 2016;26(4):309-314. doi:10.1097/MOU.0000000000000280

21. Kavia RBC, Datta SN, Dasgupta R, Elneil S, Fowler CJ. Urinary retention in women: Its causes and management. BJU Int 2006;97(2):281-7.

22. Fowler CJ, Kirby RS, Harrison MJ. Decelerating burst and complex repetitive discharges in the striated muscle of the urethral sphincter, associated with urinary retention in women. J Neurol Neurosurg Psychiatry [Internet] 1985 Oct;48(10):1004-9. Available from: http://www .ncbi.nlm.nih.gov/pmc/articles/PMC1028539/

23. Swinn MJ, Wiseman OJ, Lowe E, Fowler CJ. The cause and natural history of isolated urinary retention in young women. J Urol [Internet] 2002 Jan 1 [cited 2018 Jul 8];167(1):151-6. Available from: https://www.science direct.com/science/article/pii/S002253470565402X 